\title{
MAKNA TARI PAJAGA BONE BALLA (ININNAWA MAPATAKKO) DI KECAMATAN BUA KABUPATEN LUWU
}

\author{
Suci Rahmadani \\ Fakultas Seni Dan Desain Universitas Negeri Makassar \\ rrahmadanis323@gmail.com
}

\begin{abstract}
ABSTRAK
Penelitian ini menjawab rumusan masalah yang tercantum dalam Tari Pajaga Bone Balla (Ininnawa Mapatakko) Di Kecamatan Bua Kabupaten Luwu yaitu; 1). Penanda yang terdapat pada tari Pajaga Bone Balla (Ininnawa Mapatakko) di Kecamatan Bua Kabupaten Luwu. 2). Petanda yang terdapat pada tari Pajaga Bone Balla (Ininnawa Mapatakko) di Kecamatan Bua Kabupaten Luwu. Penelitian ini merupakan penelitian kualitatif. Penelitian ini dilaksanakan di rumah Opu Maddika Bua, jl. A. Kaddiradja Kelurahan Sakti Kecamatan Bua Kabupaten Luwu Pada Bulan November 2019 Sampai Februari 2020. Tarian ini diciptakan pertama kali oleh Wetenri Abeng sewaktu dia menjadi Datuna Bitsu untuk menolak cinta kakaknya. Data yang diperoleh dengan melakukan teknik pengumpulan data (observasi langsung, wawancara terstruktur, dan Dokumentasi). Hasil penelitian ini menunjukkan bahwa: 1). Penanda pada tari Pajaga Bone Balla (Ininnawa Mapatakko) di Kecamatan Bua Kabupaten Luwu yang meliputi ragam gerak terdiri dari 12 ragam yaitu Ma'Palappa (Bertepuk Tangan), Ma'Pammate (Mati), Ma'Tette Guntu (Memukul Lutut), Asilang (Menyilang), Ma'Camming (Bercermin), Ma'Ceppa Kanning (Ujung Alis), Ma'Riwa atau Ma'Sango (Memangku atau Menggendong Anak Bayi), Ma'Losa-Losa (Goyang-Goyang Sedikit), Ma'Pappi (Memainkan Kipas), Ma'Galeo (Memutar), Ma'Tanjeng (Beristirahat), Hormat (pamit), musik iringan terdiri dari 2 jenis irama yaitu Surru Dayya yang artinya interpal gendang pendek, dan Cakku Ridi yang artinya bunyi gendang dipukul ujung lingkaran kayunya, syair, pola lantai, penari, busana dan aksesoris, properti, tempat pertunjukkan, dan waktu/durasi. 2) Makna petanda pada tari Pajaga Bone Balla (Ininnawa Mapatakko) di Kecamatan Bua Kabupaten Luwu yaitu ragam gerak yang mempunyai makna keseluruhan yaitu nasehat-nasehat kehidupan yang sangat erat dengan adat-istiadat Masyarakat Luwu untuk bersosialisai sehari-hari dan selalu mempunyai sikap bertanggung jawab dalam diri sendiri, dan penanda dari musik iringan, pola lantai, penari, busana, akseosris, dan properti.
\end{abstract}

Kata Kunci: Makna; Tari: Pajaga Bone Balla

\begin{abstract}
This study answers the problem formulation contained in the Pajaga Bone Balla Dance (Ininnawa Mapatakko) in Bua District, Luwu Regency, namely; 1). Markers found in the Pajaga Bone Balla dance (Ininnawa Mapatakko) in Bua District, Luwu Regency. 2). Signs found in the Pajaga Bone Balla dance (Ininnawa Mapatakko) in Bua District, Luwu Regency. This research is a qualitative research. This research was conducted at the home of Opu Maddika Bua, jl. A. Kaddiradja Sakti Urban Village Bua District Luwu District from November 2019 to February 2020. This dance was first created by Wetenri Abeng when he was Datuna Bitsu to reject his brother's love. Data obtained by conducting data collection techniques (direct observation, structured interviews, and documentation). The results of this study indicate that: 1). Markers on the Pajaga Bone Balla dance (Ininnawa Mapatakko) in Bua Subdistrict, Luwu Regency which includes a variety of movements consisting of 12 variations, namely Ma'Palappa (Clapping), Ma'Pammate (Dead), Ma'Tette Guntu (Kicking the Knee), Asilang (Crosses Over), Ma'Camming (Mirror), Ma'Ceppa Kanning (Edge of Eyebrow), Ma'Riwa or Ma'Sango (Carrying or Holding a Baby), Ma'Losa-Losa (Shaking a Little), Ma'Pappi (Playing Fan), Ma'Galeo (Turning), Ma'Tanjeng (Resting), Respect (goodbye), accompaniment music consists of 2 types of rhythm namely Surru Dayya which means interpal short drum, and Cakku Ridi which means the sound of a drum being hit at the end of its wooden circle, poetry, floor patterns, dancers, clothing and accessories, property, venue, and time / duration. 2) Significance of the signaling in the Pajaga Bone Balla dance (Ininnawa
\end{abstract}


Mapatakko) in Bua District, Luwu Regency, is the variety of motions that have a whole meaning, namely life advice that is very closely related to the customs of the Luwu People to socialize everyday and always have a responsible attitude within oneself, and the Markers of accompaniment music, floor patterns, dancers, clothing, accessories, and property

Keyword: The Meaning; Dance; Pajaga Bone Balla

\section{PENDAHULUAN}

Sehubungan dengan penjelasan dan uraian di atas, maka penulis menemukan hal yang unik yang bisa menjadikan alasan khusus kenapa penulis tertarik untuk memahami dan mengangkat lebih lanjut tentang Tari tradisional Pajaga Bone Balla terutama Tari Ininnawa Mapatakko. Tari Ininnawa Mapatakko mempunyai makna dalam setiap ragam geraknya dan makna keseluruhan dari ragam-ragam tersebut yaitu nasehat-nasehat kehidupan yang sangat erat dengan adat-istiadat Masyarakat Luwu untuk bersosialisai di dalam kehidupan sehari-hari dan selalu mempunyai sikap bertanggung jawab dalam diri sendiri. Selain itu, masih banyak generasi muda-mudi Masyarakat Luwu yang belum tau dan memahami makna yang terkandung dalam Tari Ininnawa Mapatakko. Maka penulis tertarik mengangkat judul "Makna Tari Pajaga Bone Balla (Ininnawa Mapatakko) di Kecamatan Bua Kabupaten Luwu" agar tidak mengalami kepunahan dan dapat dikenal baik oleh generasi-genarasi berikutnya yang ingin mengetahui dan mempelajari tarian ini.

Rumusan masalah dalam penelitian adalah sebagai berikut. Bagaimana penanda yang terdapat pada tari Pajaga Bone Balla (Ininnawa Mapatakko) di Kecamatan Bua Kabupaten Luwu? dan Bagaimana petanda yang terdapat pada tari Pajaga Bone Balla (Ininnawa Mapatakko) di Kecamatan Bua Kabupaten Luwu?

Adapun tujuan dari penelitian ini, untuk mendeskripsikan penanda yang terdapat pada tari Pajaga Bone Balla (Ininnawa Mapatakko) di Kecamatan Bua Kabupaten Luwu; dan untuk mendeskripsikan petanda yang terdapat pada tari Pajaga Bone Balla (Ininnawa Mapatakko) di kecamatan Bua Kabupaten Luwu.

Sehingga diharapkan dapat memberi manfaat sebagai bahan masukan bagi peneliti untuk memahami tari Pajaga Bone Balla (Ininnawa Mapatakko) di Kecamatan Bua Kabupaten Luwu, dan sebagai bahan pegangan dan evaluasi bagi peneliti lain yang hendak menindak lanjuti topik yang akan di angkat

\section{METODE PENELITIAN}

Jenis Penelitian ada dua macam, yaitu Penelitian Kuantitatif dan Penelitian Kualitatif. Penelitian Kuantitatif adalah penelitian ilmiah yang sistematis terhadap bagian-bagian dan fenomena serta hubungan-hubungannya. Sedangkan, Penelitian Kualitatif adalah penelitian eksploratif yang biasanya lebih bersifat studi kasus. Data penelitian kualitatif merupakan sumber teori atau teori berdasarkan data. Kategori-ketegori dan konsep-konsep dikembangkan oleh peneliti dilapangan (Halilintar: 2016: 39-40).

Pada penelitian ini penulis mengangkat sasaran pada penanda dalam tari tersebut dan petanda ragam gerak Tari Pajaga Bone Balla (Ininnawa Mappatakko) di Kecamatan Bua Kabupaten Luwu, serta hal-hal pendukung lainnya seperti kostum, aksesoris, musik iringan, tempat pertunjukan, waktu/durasi, dan penari.

Responden menurut Suharsimi Arikunto adalah orang-orang yang merespon atau menjawab pertanyaan penelitian baik pertanyaan tertulis maupun lisan (2003: 10).

Teknik ini menjadi landasan dalam penelitian tari Pajaga BoneBalla (Ininnawa Mapatakko) karena dalam teknik ini peneliti dapat mencari dan membaca buku referensi yang berkaitan tentang permasalahan, informasi, maupun teori-teori yang berkaitan dengan tari (Halilintar: 2017: 17).

Dalam teknik peneliti melakukan observasi langsung atau mengamati langsung tentang tari Pajaga Bone Balla (Ininnawa Mapatakko) agar mendapatkan data secara keseluruhan dari objek yang akan diteliti dengan cara mengamati, mencatat dan mendokumentasikan tentang hal-hal yang menjadi permasalahan ataupun informasi penting bagi peneliti tentang tari Pajaga Bone Balla (Ininnwa Mapatakko).

Adapun jenis-jenis wawancara yaitu, wawancara bebas atau tidak terstruktur, 
wawancara terstruktur, wawancara semiterstruktur, dan wawancara mendalam.

Dokumentasi adalah salah satu teknik pengumpulan data dengan cara mencari sumber yang ada kaitannya dengan penelitian, pengumpulan data yang dilakukan dengan cara mengumpulkan dokumen-dokumen yang berkaitan dengan Makna Tari Pajaga Bone Balla (Ininnawa Mapatakko) Kecamatan Bua Kabupaten Luwu.

Dalam penelitian kualitatif analisis data dilakukan selama dan setelah pengumpulan data. Analisis data bertujuan untuk mengidentifikasi seluruh data yang terkumpul, menyajikan, dan memaknai data terebut (Halilintar: 2016: 157). Teknik analisis data kualitatif (analisis non statistk) dilakukan dengan langkah-langkah yaitu, reduki, penyajian data, dan

\section{HASIL PENELITIAN DAN PEMBAHASAN Hasil Penelitian}

\section{Sekilas Tentang Kerajaan Luwu atau Kabupaten Luwu}

Luwu yang dikenal juga dengan sebutan Lu' atau Luhu merupakan kerajaan tertua dan berpengaruh di Sulawesi Selatan. Ada beberapa pendapat yang menjelaskan tentang makna kata Luwu, Lu' atau Luhu, antara lain yaitu luwu bermakna, bumi atau wilayah. Luwu berarti Riulo (berasal dari bahasa Bugis Kuno) yang berarti diulur. Sebuah daerah yang dihamparkan dan ditaburi dengan kekayaan alam yang melimpah, dan menjadi satu daerah atau kerajaan pusaka (ongko) (Anwar: 2013: 2).

\section{Sekilas Tentang Tari Pajaga}

Asal mulanya diberi nama Tari Pajaga yaitu, dalam peningkatan kepercayaan rakyat Luwu dan setelah masuknya agama Islam pada saat itu menjadi agama Kerajaan Luwu (tahun 1604). Maka tari ini tidak lagi menajdi tari hiburan raja-raja bahkan menjadi tari penghormatan kepada tamu-tamu Raja yang datang ditarikan pada saat-saat tertentu, seperti pada upacaraupacara kerajaan. Oleh karena tari tersebut sering dipertunjukkan pada malam hari di saat-saat pengawal atau pengawas sedang menjaga keselamatan Raja, dimana rakyat ikut pula menyaksikannya sehingga tari itu diberi nama Tari Pajaga artinya pengawal, jadi tari tersebut adalah Tari Pengawal (Munasiah: 1982: 91-92).

\section{Penanda Pada Tari Tari Pajaga Ininnawa Mapatakko}

\section{Ragam Gerak}

1) Ma’ Palappa (Bertepuk Tangan)

Penanda pada ragam pertama menurut Opu Maddika Bua pada tanggal 17 November 2019 yaitu saling mempertumakan kedua telapak tangan atau seperti bertepuk tangan dengan tangan kanan menghadap ke atas dan tangan kiri menyamping ke kanan, ragam ini sering disebut Ma'palappa atau biasa juga dinamakan Pa'lappa.

\section{2) Ma' Pammate (Mati)}

Pada ragam ini menurut Opu Maddika Bua pada tanggal 17 November 2019 terdapat Penanda gerak yaitu tangan kanan ditekuk keatas dan tangan kiri diluruskan sedikit kesamping. Gerakan ini adalah gerakan transisi atau penutup selesai melakukan gerak. Gerakan ini selalu ada di setiap ragam ragam tari Pajaga Bone Balla.

3) Ma'Tette Guntu (Memukul Lutut)

Ragam ke empat ini menurut Opu Maddika Bua Pada tanngal 17 November 2019 mempunyai penanda yaitu menghentakkan atau memukul kipas di samping lutut.

4) Asilang (Menyilang)

Gerakan ini terdapat Penanda menurut Opu Maddika Bua pada tanggal 17 November 2019 yaitu kedua tangan disilangkan di depan badan sejajar dengan pusar, Pajag-Pajaga sering menyebutkan silang mebentuk angka romawi $\mathrm{X}$ yang artinya sepuluh, bukan tanda $\mathrm{X}$ yang berarti salah. Gerakan ini adalah gerakan transisi, setiap ragam gerak selesai dan akan dilanjutkan kembali ke ragam gerak yang baru maka para penari memberikan tanda Asilang terlebih dahulu.

\section{5) Ma' Camming (Bercermin)}

Penanda pada ragam ke lima yaitu menutup muka menggunakan kipas seolah-olah sedang bercermin dan di samping penari yang sedang melakukan Ma'camming mereka melakukan Ma'ceppa kanning menurut Opu Maddika Bua pada tanggal 17 November 2019. 


\section{6) Ma’ Ceppa Kanning (Ujung alis)}

Gerakan ini memiliki penanda menurut Opu Maddika Bua pada tanggal 17 November 2019 berupa tangan dibawa keatas menyentuh alis kemudian turun secara perlahan. Ketika para penari barisan tengah melakukan ragam gerak Ma'Camming maka penari disamping kiri dan kanan melakukan ragam gerak Ma'Ceppa Kanning.

7) Ma' Riwa atau Ma' Sango (Memangku atau Mengendong Anak Bayi).

Penanda menurut Opu Maddika Bua pada tanggal 17 November 2019 pada ragam ini yaitu tangan yang memegang kipas di depan pusar dan tangan kiri di atas kipas seperti sedang mengendong anak bayi, sedangkan menurut Opu Sadda pada tanggal 20 November 2019 pada ragam ini mempunyai nama yaitu Ma'sango tetapi mempunyai arti dan penanda yang sama. Para penari melakukan ragam gerak Ma'Riwa atau Ma'Sango pada barisan tengah dan disamping barisan kiri dan kanan melakukan ragam gerak Ma'Pappi.

8) Ma'Losa-losa (Goyang-goyang Sedikit)

Gerakan ini menurut Opu Maddika Bua pada tanggak 17 November 2019 mempunyai Penanda yaitu tangan kanan yang memegang kipas lurus ke samping bawah dan tangan kiri diayunkan lurus ke depan sejajar dengan dada.

\section{9) Ma’ Pappi (Memainkan Kipas)}

Penanda pada ragam ke Sembilan ini menurut Opu Maddika bua pada tanggal 17 November 2019 yaitu kedua tangan sambil memegang kipas dibawa turun ke bawah depan sejajar dengan pinggang kemudian dihentakkan.

\section{0) Ma' Galeo (Memutar)}

Ragam ini memiliki tanda menurut Opu Maddika Bua pada tanggal 17 November 2019 berupa memakai properti kipas dan tidak menggunakan kipas kemudian pergelangan tangan diputar melawan arah jarum jam. Gerakan ini ada yang berdiri dan ada juga yang pada saat penari duduk.

\section{1) Ma’ Tanjeng (Beristirahat)}

Penanda pada ragam ini menurut $\mathrm{Opu}$ Maddika Bua pada tanggal 17 November 2019 yaitu duduk dengan kaki kiri dilipat dan kaki kanan ditekuk sedikit keatas dan kedua tangan di belakang menopang badan.

\section{2) Hormat (Pamit)}

Penanda pada ragam terakhir menurut Opu Maddika Bua pada tanggal 17 November 2019 yaitu melipat kedua tangan kedepan dada dan kedua telapak tangan bersentuhan memberikan gerakan salam kepada yang menonton pertunjukkan para penari Pajaga.

\section{Musik Iringan}

Musik iringan pada tarian ini sekarang hanya menggunakan dua buah gendang. Menurut Andi Sa'dda pada tanggal 20 November 2019 setelah mendengar rekaman tarian, didalam iringannya tedapat 2 (dua) jenis nama nada atau irama yang digunakan yaitu Surru Dayya yang artinya interpal gendang pendek dan Cakku Ridi yang artinya bunyi gendang dipukul ujung lingkaran kayunya yang ditandai dengan satu kali memukul gendangnya lalu berpindah ke ujung lingkaran kayu gendangnya.

\section{Syair}

Adapun Syairnya sebagai berikut:

Ininnawa Mapatakko

Wahai Jiwa Yang Tenag

Alai Pakka Waru

Jadikanlah Obat

Toto' Talle Sangmu

Takdir Yang Akan menimpahmu

\section{Pola Lantai}

Pola lantai yang digunakan dalam tari Pajaga Ininnawa Mapatakko masih mempertahankan keasliaanya yang mempunyai ciri khas pola lantai tari tradisional lainnya yaitu hanya berbentuk lingkaran, Ma'Polo Rua (Patah Dua) dan Ma'Polo Tellu (Patah Tiga).

\section{Penari}

Penari yang melakukan tarian ini menurut Opu Maddika Bua pada tanggal 17 November 2019 dulunya hanya dari kalangan bangsawan dan dari semua jenis umur dimulai dari anak kecil yang telah dilatih menari dan telah memenuhi semua persyaratan dari kerajaan. Setelah gadis, mereka diikut sertakan di atas panggung untuk mementaskan tarian yang telah bertahun-tahun 
diajarkan sampai mereka bersuami dan sudah memiliki anak masih bisa dipanggil untuk menari asalkan selama mereka masih bisa menari, mampu untuk menarikan tarian-tarian pajaga, dan bisa mengontrol fisik agar tidak kelihatan lelah di atas panggung. Penari yang sudah bersuami biasa disebut makamummu.

\section{Busana dan Aksesoris}

Sanggar Opu Maddika Bua Seiring berjalannya waktu perhiasan sambang tidak digunakan lagi karena pakaian yang digunakan sudah berbahan tebal hanya menggunakan perhiasan Bunga Simpolong atau kembang sanggul, Patandra atau bando, Lola atau gelang, Bangkara atau anting-anting, dan Mastura, Kolara atau kalung, simak atau pengikat baju lengan yang mayarakat Luwu menyebutnya Sima Taiyya, Simbolo Tottong (rambut palsu atau konde') untuk lebih memperindah tarian Pajaga pada saat ditampilkan atau dipentaskan.

\section{Properti}

Properti yang digunakan oleh penari masih sangatlah sederhana yaitu selendang atau Pa'sari yang kegunaannya untuk mengantung kipas dan satu buah kipas yang indah buatannya, bikinan orang-orang Luwu itu sendiri.

\section{Tempat Pertunjukkan}

Setelah pergeeseran zaman, sekarang telah dapat dipertunjukkan di luar istana jika ada acara-acara penting Luwu misalnya hari jadi Kabupaten Luwu, acara pernikahan keturunan bangsawan, dan berbagai lomba-lomba yang ada di Kabupaten Luwu maupun di Kabupaten lainnya bahkan di berbagai Negara.

\section{Waktu/Durasi}

Seiring berjalannya waktu menurut Andi Abdullah Saanad Kaddiradja maka tarian ini berubah durasi menjadi 30 menit saja tetapi pada saat acara-acara resmi maupun festival-festival maka tarian ini berdurasi 7 menit sampai 10 menit saja yang tadinya setiap ragam gerakannya masing-masing 3 kali pengulangan menjadi hanya satu kali pengulangan dalam setiap ragam geraknya.

\section{Petanda pada Tari Pajaga Ininnawa Mapatakko}

\section{Ragam gerak}

\section{1). Ma’Palappa (Bertepuk tangan)}

Pada ragam pertamapenari menurut Opu Maddika Bua pada tanggal 17 November 2019 mempunyai dua makna penanda. Pertama, menggambarkan dan memperlihatkan ekspresi kegembiraan dan kesenangan hatinya maupun kecerian melalui gerakan ini kepada tamu-tamu agung dan juga penonton lainnya yang sedang menyaksikan, mereka menunjukkan lewat bahasa tubuh karena mimik muka tidak dimainkan oleh penari sebab penari hanya bisa memandang arah bawah mulai dari menari sampai selesai menari. Kedua, memngambarkan cara membersihkan tangan yang penuh dengan debu, ini menceritakan jika ingin melakukan atau mengerjakan sesuatu harus terlebih dahulu membersihkan diri dengan cara berwudhu yang dimulai dengan membasuh kedua tangan.

\section{2). Ma'Pammate (Mati)}

Penari melakukan gerakan ini mempunyai arti menurut Opu Maddika Bua pada tanggal 17 November 2019 yaitu memberitahukan dan menasehati setiap pekerjaan yang dilakukan harus mengerjakannya dengan sungguh-sungguh dan terlebih dahulu selesai pekerjaan satu kemudian pindah mengerjakan pekerjaan lainnya.

\section{3). Asilang (Menyilang)}

Pada saaat gerakan Asilang menurut Opu Maddika Bua pada tanggal 17 November 2019 penari menyimbolkan tandanya dengan angka romawi X (sepuluh) yang berarti selesai bukan salah. Maksudnya, bahwa ketika melakukan suatu proses ragam tarian itu sediri harus selesai kemudian pindah atau beralih ke ragam lainnya dan ketika ada orang meninggal di Luwu pada zaman dulu maka simbol yang digunakan berbentuk Asilang atau biasa disebut Makatampang tapi sekarang diganti menjadi kain putih yang artinya pekerjaannya selama di dunia telah selesai dan pindah ke tempat lainnya.

\section{4). Ma’Tette Guntu (Memukul Lutut)}

Ragam keempat menurut Opu Maddika Bua pada tanggal 17 November 2019 bermakna tentang seorang anak bayi yang baru dilahirkan di bumi tumbuh dan berkembang menjadi balita kemudian diajarkan untuk berjalan oleh ibunya. Pada zaman dahulu anak kecil Luwu yang baru lahir terutama bagi anak kalangan bangsawan harus diurut badannya terutama tangan, kaki, dan 
tempurung lututnya keduanya bersamaan di putar sambil meluruskan kakinya agar anak mereka dapat cepat dan lancar berjalan dan menjadi seorang anak yang belajar memulai sesuatu (mandiri) dan bertanggung jawab dalam setiap langkah yang dia pilih.

\section{5). Ma'Camming (Bercermin)}

Pada ragam ini makna yang terkandung dalam tari Ininnawa Mapatakko menurut Opu Maddika Bua pada tanggal 17 November 2019 yaitu ketika manusia sudah melakukan aktifitas atau pekerjaannya harus selalu mengevaluasi diri dan melihat kelebihan dan kekurangan diri sendiri sehingga secepatnya dapat diperbaiki dan bisa mengkontrol dirinya sejak dini untuk menjadi pribadi yang lebih baik dan dapat berguna untuk masyarakat masyarakat di masa depan.

\section{6). Ma'Ceppa Kanning (Ujung Alis)}

Makna yang terkandung dalam ragam ini menurut Opu Maddika Bua pada tanggal 17 November 2019 yaitu jika selesai mengevaluasi diri dan melihat kelebihan dan kekurangan diri maka harus berpikir apa yang harus dilakukan agar bisa keluar dan menemukan cara yang baik menyelesaikan masalah yang ada di dalam diri sendiri.

\section{7). Ma'Riwa atau Ma'Sango (Mengendong atau Memangku)}

Menurut Opu Maddika Bua pada tanggal 17 November 2019 ragam ini mempunyai arti memangku yang diberi simbol anak kecil artinya segala sesuatu yang akan ditakdirkan harus tetap diterima dengan senang hati, jika diberikan sesuatu pekerjaan atau memilih suatu pekerjaan haruslah mepertanggung jawabkan dan menyelesaikan pekerjaan tersebut dengan bersungguh-sungguh agar mendapatkan hasil yang terbaik dan orang yang melihat atau memberikan pekerjaan kepada kita dapat percaya dan senang melihat hasil kerja yang dilakukan diri sendiri.

\section{8). Ma'Losa-Losa (Goyang-Goyang Sedikit)}

Ragam kedelapan ini mempunyai makna menurut Opu Madika Bua pada tanggal 17 Noveber 2019 yaitu sepanjang usaha yang penari kerjakan selama menghibur penonton atau rajaraja mereka ingin menunjukkan atau membuktikan bahwa mereka telah memberikan hasil yang terbaik dan telah semangat dan mengeluarkan tenaga yang maksimal untuk melaksanakan tanggung jawab yang telah mereka kerjakan dan akan mereka selesaikan.

\section{9). Ma'Pappi (Memainkan Kipas)}

Menurut Opu Maddika Bua pada tanggal 17 November 2019 Penari mempunyai bukti bahwa telah melakukan atau sedang melakukan sesuatu pekerjaan tetapi ditengah pekerjaan itu mereka ingin beristirahat karena lelah dan letih seharian melaksanakan pekerjaan tersebut maka yang dilakukan mereka memberi tanda kepada atasannya bahwa dia ingin beristirahat karena jika mereka ingin berbicara langsung kepada atasannya itu merupakan perbuatan kurang sopan.

\section{0). Ma'Galeo (Memutar)}

Gerakan ini mempunyai makna menurut Opu Maddika Bua pada tanggal 17 November 2019 pekerjaannya telah diseleaikan dengan baik dan indah tetapi penari ingin melihat kembali apakah ada yang salah dalam pekerjaan tersebut dan memperbaikinya segera mungkin agar terlihat lebih baik atau lebih indah lagi dilihat oleh penonton yang dia hibur dan agar mereka yang menontontarian yang mereka persembahkan.

\section{1). Ma'Tanjeng Bersandar)}

Pada ragam ini menurut Opu Maddika Bua pada tanggal 17 November 2019 saat memberikan tanda-tanda bahwa penari telah lelah dan pekerjaannyapun telah hampir selesai maka dia ingin betul betul beristirahat sebelum mengerjakannya kembali dan duduk bersandar dengan dua tangan di belakang untuk menopang badannya sebagai sandaran karena mereka tidak mempunyai kursi yang bisa diduduki maupun kursi yang mepunyai sandaran karena masih sedang melakukan pekerjaan yaitu menghibur para prajurit-prajurit yang berada di depannya.

\section{2). Hormat (Pamit)}

Ragam terakhir bermakna menurut Opu Maddika Bua pada tanggal 17 November 2019 memberitahukan kepada raja-raja atau para bangsawan yang ada di dalam istana bahwa pekerjaan mereka telah selesai dan ingin mengucapkan terimakasih dan memberikan rasa sopan santun karena telah diperbolehkan menari dan menyelesaikan pekerjaannya hingga selesai dengan baik kemudian pamit untuk beritirahat dan 
pulang kerumahnya atau kamarnya masingmasing.

\section{Musik Iringan}

Muik Iringan pada tarian ini menurut Andi Sa'dda pada tanggal 20 November 2019 mempunyai dua jenis nama nada atau irama yaitu Surru Dayya dan Cakkru Ridi.

\section{Pola Lantai}

\section{1). Lingkaran}

Pola lantai lingkaran mempunyai makna seperti para prajurit-prajurit yang bertugas di dalam Istana maupun luar Istana agar selalu waspada terhadap sekelilingnya.

\section{2). Ma'Polo Rua dan Ma'Polo Tellu}

Ma'Polo Rua dan Ma'Polo Tellu menurut Opu Madika Bua pada tanggal 17 November 2019 artinya memotong atau membuat barisan yang bermakna Politis yaitu pada saat pemerintahan Luwu prajurit-prajurit yang akan turun perang maupun telah selesai dari perangnya harus dipimpin oleh pimpinannya masing-masing, mereka tidak menerima perintah atau menjalankan perintah tersebut jika bukan dari pimpinannya masing-masing.

\section{Penari}

\section{1). Jenis Kelamin}

Penari pada tari Pajaga Ininnawa Mapatakko berjenis kelamin perempuan hal ini bermakna dari arti Pajaga Bone Balla yaitu penjaga atau pengawal isi rumah dan isi rumah itu adalah perempuan. Jadi perempuan yang berjagajaga dan mawas diri dalam rumah jika para prajurit dan raja sedang melakukan perang di luar Istana menurut Opu Madika Bua pada tanggal 17 November 2019.

\section{2). Usia Penari}

Menurut Opu Madika Bua pada tanggal 17 November 2019 usia umum dalam melakuakan tari Pajaga Ininnawa Mapatakko ini tidak terbatas yaitu mulai dari berusia dini dilatih dari kecil sampai dia pandai menarikan tarian tersebut, hal ini dikarenakan dari kecil kita diajarkan bagaimana menjaga sikap sopan, lemah lembut, santun, dan selalu bersabar.

\section{3). Jumlah Penari}

Jumlah penari dalam tarian ini menurut Opu Madika Bua pada tanggal 17 November 2019 berjumlah 12 orang dan tidak boleh ganjil, harus seimbang, karena mempunyai makna mengikuti jumlah pemangku adat di dalam Istana berjumlah 12 orang yang dinamakan Adat Sampulo Dua..

\section{Busana}

\section{1) Baju Bodo atau Waju Tokko}

Warna baju merah adalah warna umum untuk gadis dan wanita sudah kawin, hijau adalah warna khusus untuk gadis-gadis, ungu adalah warna untuk wanita yang lanjut umur, kuning adalah warna untuk bangsawan tinggi, dan hitam warna untuk wanita tua (Kasim: 1980: 6).

\section{2). Rante Sampu' atau Rok}

Keturunan Bangsawan yang berada di daerah Kerajaan atau Kabupaten Luwu Menurut Opu Ancung pada tanggal 5 Maret 2020 dahulu hanya menggunakan sarung sutera yang merupakan ciri khas adat Luwu tetapi setelah masuknya Negara Lain seperti China dan India maka Raja dan Ratu yang berada di Luwu membuat busana mereka sendiri sehingga dibuatlah Rante Sampu' bersusun dua dan menjadi trend hingga sekarang di Kerajaan atau Kabupaten Luwu.

\section{Aksesoris}

\section{1). Pinang Goyang}

Dahulu kala yang menarikan tarian Pajaga tidak memakai perhiasaan di atas kepala, tetapi setelah Negara Asing masuk ke wilayah Luwu maka penari Pajaga Luwu memakai pinang goyang di atas kepalanya untuk mempercantik diri dan berubah menjadi Patandra atau Bando agar rambutnya terlihat rapi sebab orang dulu belum mengenal hairspray hal ini dikemukankan oleh Andi Abdullah Sanaad Kaddiradja pada tanggal 5 Maret 2020.

\section{2). Patandra atau Bando}

Makna dari perhiasan ini menurut Andi Abdullah Sanaad Kaddiradja pada tanggal 5 Maret 2020 yaitu mepercantik dan kelihatan bagus ketika menyangga sanggul agar sanggul yang dikenakan tidak jatuh saat melakukan Pajaga 
karena dahulu orang-orang belum mengenal hairspray.

\section{3). Bangkara atau anting}

Andi Abdullah Sanaad Kaddiradja pada tanggal 5 Maret 2020 mengatakan perhiasan ini terbagi menjadi tiga bagian. Pertama bernama Bangkara untuk kalangan menengah ke bawah, kedua bernama Sunti untuk kalangan menengah ke atas dan terakhir bernama Anting untuk masyarakat umum yang ada di Luwu.

4). Mastura

Andi Abdullah Sanaad Kaddiradja pada tanggal 5 Maret 2020 mengatakan bahwa Perhiasan ini adalah ciri khas bangsawan dari Luwu, jika memakai perhiasan ini maka orang awam akan paham mereka adalah keturunan bangsawan Luwu.

\section{5). Gieno Kiana atau Kalung}

Opu Sa'dda pada tanggal 5 Maret 2020 mengatakan Gieno Kiana atau rantai yang bersusun berjumlah 9 sebagai simbol untuk menutup 9 lubang yang terdapat pada diri setiap orang, seperti lubang hidung, telinga, mata, mulut, kemaluan, dan pantat karena sembilan lubang ini sering terpengaruh oleh nafsu duniawi oleh sebab itu secara simbolik perlu ditutup.

\section{6). Sima Taiyya atau Pengikat Lengan Baju}

Sima dapat diartikan sebagai jimat, sehingga Sima Taiyya selain sebagai hiasan juga berfungsi sebagai jimat penangkal guna-guna yang akan ditujukan kepada pengantin perempuan. Untuk keturunan Bangsawan, Sima Taiyya dipakai bersusun dua, sedangkan untuk keturunan To Sama hanya satu saja (tidak bersusun) (Anwar: 2017: 367).

\section{7). Gelang}

Perhiasan gelang menurut Andi Abdullah Sanaad Kaddiradja pada tanggal 5 Maret 2020 mengatakan gelang terbagi menjadi 3 bagian yang pertama disebut Tinggoro Tedong yaitu perhiasan yang sangat penting dan hanya kalangan atas atau bangsawan yang mempunyai perhiasan ini, yang kedua dinamakan Lola untuk masyarakat umum Luwu, dan ketiga Potto untuk kalangan menegah ke bawah.

\section{8). Sambang}

Andi Abdullah Sanaad kaddiradja pada tanggal 5 Maret 2020 Sambang makna perhiasan ini sebagai pengikat sarung bukan untuk menutupi kemaluan.

\section{Properti}

Passapu dengan Eruk-Eruk. Passapu artinya Selendang dan Eruk-Eruk yaitu semacam palet atau pengasih bertujuan agar yang melihatnya suka atau tertarik pada saat menari.

\section{Pembahasan}

Tari Pajaga Bone balla diciptakan pertama kali oleh Andi Wetenri Abeng untuk menolak cinta kakaknya yang bernama Sawerigading maka diciptakan sebuah gerakan meditasi atau gerakan bissu di Botting Langit karena Andi Tenri Abeng lebih hebat dari Sawerigading, segala hal yang belum diketahui di bumi Andi Tenri Abeng sudah mengetahui terlebih dahulu atau yang biasa disebut mempunyai indera ke enam. Tarian ini ditarikan oleh satu orang yang diberi nama tari Sajo atau tari tunggalberawal dari sini kemudian muncullah koreografer-koreografer lainnya dan terciptalah tarian pertama yaitu tari Pawinru dan tari-tari lainya yang berjumlsh 12 macam tarian yang kemudian disatukan dan berubah nama menjadi Tari Pajaga Bone Balla yaitu tari penjaga isi istana, tetapi yang bisa diselamatkanhanya 6 macam tarian saja yang bisa diselamatkan, karena adanya peperangan zaman revolusi Belanda.

\section{KESIMPULAN DAN SARAN \\ Kesimpulan}

Tari Pajaga Ininnawa Mapatakko adalah salah satu tari tradisional dari Luwu yang pada mulanya diciptakan tarian ini untuk menolak cinta kakaknya. Kemudian tarian ini berkembang didalam lingkungan istana kerajaan yang berfungsi sebagai penghibur para prajurit-prajurit yang akan berperang maupun pulang dari berperang, ajang pencarian jodoh, persembahan tamu kerajaan, dan upacara perkawinan para bangsawan. Tarian ini mempunyai ragam gerak berjumlah 12 yaitu Ma'palappa, Ma'tette Guntu, Ma'pammate. Asilang, Ma'camming, Ma'ceppa Kanning, Ma'riwwa atau Masango, Ma'papi, Ma'losa-losa, Ma'galeo, Ma'tanjeng dan Hormat yang setiap ragamnya mempunyai makna tersendiri. Tari ini memiliki makna keseluruhan yaitu memberikan nasihat-nasihat tentang betapa 
pentingnya semua pekerjaan yang telah dipilih maupun yang akan dikerjakan dan sudah selesai semua harus mempunyai tanggung jawab yang besar baik itu ke diri sendiri, orang lain, dan agama.

\section{Saran}

1. Diperlukan dukungan dari pemerintah setempat khusunya tarian-tarian yang sudah hampir hilang

2. Penulis menaruh harapan agar tari tersebut masih ditarikan dan berfungsi sebagaimana mestinya

\section{DAFTAR PUSTAKA}

Anwar, Idwar. 2012. Sejarah dan Kebudayaan Luwu SMA Kelas X Cetakan Ketiga. Pustaka Sawerigading: Arung Pustaka (Dinas Perpustakaan dan Kearsipan Kabupaten Luwu)

Anwar, Idwar. 2017. Ensiklopedia Kebudayaan Luwu. Komunitas kampung Sawerigading (KAMPUS)

Arikunto, Suharsimi. 2003. Prosedur Penelitian, Suatu Praktek. Jakarta: Bina Aksara

Kasim, H. Andi. 1980. Pajaga. Ujung Pandang: Proyek Pengembangan Kesenian Propinsi Sulawesi Selatan 